\title{
A Gestão de Cemitérios em seu âmbito público e privado
}

Anny Laryssa Oliveira de Almeida (IFRN) annylaryssa62@gmail.com

Anyelly Rodrigues Simplício (IFRN) anyrsimp@gmail.com

Paola Kamily Araújo Rodriguez (IFRN) paolarauj@gmail.com

Viviane Cavalcante Silva (IFRN) cavalcanteviviane.200@gmail.com

\section{Resumo}

O presente artigo traz uma análise e comparação da gestão de cemitérios em seu âmbito público e privado. O objetivo da pesquisa foi estabelecido com foco em apontar as principais diferenças em ambas as gestões, enfatizando a importância de uma boa administração neste tipo de serviço e seu impacto socioambiental. Por meio de entrevistas foram coletadas informações do Grupo Vila representando as características do serviço privativo e por meio de pesquisas online foram analisadas algumas situações e características da rede pública de cemitérios de Natal/RN. Também foram enfatizadas questões ambientais e modelos de necrópoles.

Palavras-Chaves: Cemitérios; Gestão; Público; Privado; Meio Ambiente.

\section{Introdução}

A gestão de estoque pode ser definida como um meio de organização e administração dos materiais ou mercadorias presentes nas mais diversas organizações (PARÍSIO, 2014), tal gestão é essencial para o desenvolvimento da composição de uma empresa, seja ela privada ou pública, tais como: escolas, hospitais, indústrias, cemitérios e entre outros. Manter um estoque de grande porte pode acarretar problemas e preocupações para a empresa como riscos de deterioração, danos, perda ou até mesmo roubo.

Sendo uma das chaves para o sucesso das empresas, tendo em vista que busca otimizar processos e melhorar resultados, a gestão de estoques muitas vezes encontra dificuldade em alguns setores. Estoque insuficiente, por exemplo, a falta de produtos pode gerar problemas incontáveis, alguns deles são a perda da confiança de clientes, anulação de grandes contratos e de vendas futuras. Falta de Inventário físico é mais uma complicação encontrada pela gerência de estoques, muitos gestores acabam não efetivando inventários regularmente e 
confiam nas quantidades que constam em seus controles, o que pode acarretar compras indevidas e/ou falta de estoque em época de pico. Excesso de estoque é mais um empecilho para cumprir a missão da gestão de estoques, quando referido a produtos perecíveis, tem-se perda total de estoque, gerando a empresa uma despesa desnecessária por ter investimento paralisado.

Em um serviço tão distinto como o ramo de cemitério, a administração também possui algumas problemáticas envolvendo a estocagem de féretros, que serão expostas ao decorrer desta pesquisa, que trará análises sobre o giro de estoques nas covas, o controle de informações, o mapeamento do espaço e o impacto ambiental gerado por essa aplicação, que apresenta uma má gestão principalmente quando se trata da rede púbica.

Diante do exposto, o objetivo desta pesquisa é analisar a gestão das necrópoles da rede pública e privada fazendo uma comparação entre elas, observando os principais problemas do ramo e evidenciado a necessidade de uma boa gestão de estoque para este tipo de organização, sendo assim, de acordo com os dados coletados, analisar uma possível solução para problemáticas relacionadas.

\section{Referencial teórico}

Os cemitérios são os locais onde são sepultados os corpos de entes queridos, estes locais geralmente envolvem práticas religiosas e têm uma grande conexão sentimental com seus clientes, por isso, é importante que estes espaços estejam bem conservados e que tenham uma boa gestão, para não haver transtornos com seus utilizadores em momentos de instabilidade emocional.

Estes transtornos começam no fato de a demanda de um cemitério ser variável, e os problemas se acentuam quando se trata do âmbito público, que sofre com a superlotação e a má estruturação, o que causa o desconforto das famílias que têm seus entes sepultados nestes locais.

A gestão pública das necrópoles é feita pelo governo ou por terceiros, que disponibilizam o terreno para o sepultamento através de uma autorização dada à família para realizar o enterro, sendo assim, somente o terreno é oferecido pelo Estado, outros custos, tais como: construção do túmulo, decoração e manutenção das sepulturas são de reponsabilidade dos familiares, mostram os grupos funerários Bosque da Esperança e Parque Renascer de 
Belo Horizonte, em seu informativo fundamentado na legislação brasileira vigente em 2017, apresentando a lei de direito à sepultura (jus sepulchri).

\begin{abstract}
'Jus Sepulchri', em síntese, é o direito a ser sepultado, direito de permanecer sepultado, direito à sepultura ou direito sobre a sepultura e direito de sepultar. É um direito subjetivo de todo homem que decorre da dignidade do ser humano, perante seus semelhantes e perante Deus. Esta dignidade (atributo da ordem moral) é garantida pelo direito natural e encontra-se no direito positivo em decorrência da atribuição da personalidade jurídica a cada ser humano nascido com vida, independentemente de qualquer outro requisito formal. (ARAÚJO, 2015)
\end{abstract}

Isto acarreta algumas consequências como a estrutura precária destes locais, já que o governo não intervém nestes quesitos, deixando a conservação nas mãos da população utilizadora da localidade, a intervenção do Estado é feita quando é necessária a movimentação da ossada, para a liberação de mais túmulos, algumas famílias tentam adquirir a cova pelo direito a perpetuidade, o que geralmente não é possível exatamente por causa da superlotação e demanda instável nestes cemitérios, que possuem uma grande movimentação de estoque por estas razões.

Um estudo de caso feito por Luciano Sacramento de Paula e Francisco Santos Sabbadini (UNESA, 2005) no cemitério municipal de Resende, Rio de Janeiro, apontou que somente $2 \%$ das jazidas lá localizadas, são de perpetuidade, evidenciando a dificuldade e a quase impossibilidade, de obter um túmulo pela gestão pública.

Figura 1 - Túmulos de perpetuidade e temporários

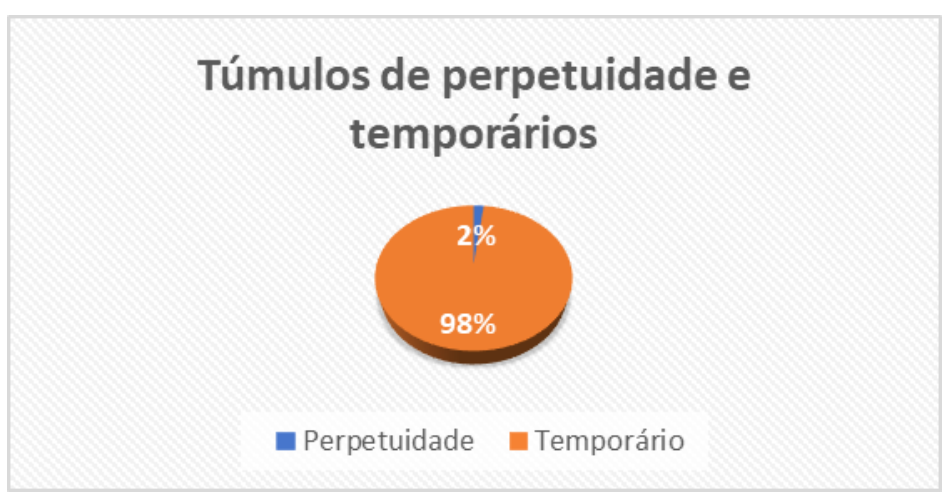

Fonte: Adaptado de PAULA, L. S. (2005)

Agora analisando o âmbito privado, a movimentação de estoque não é tão constante, já que as covas são construídas apenas após a solicitação do cliente, e que depois da aquisição, aquele local pertence exclusivamente à ele, a movimentação do material funerário é feito apenas com a autorização do proprietário daquela jazida, e a manutenção e higienização é de 
responsabilidade da empresa, que é privada mas por causa de sua área de atuação, precisa de supervisão governamental.

Um ponto que deve ser observado em ambas as gestões, é a questão ambiental, que não é bem valorizada principalmente no setor público, que conta com locais impróprios para esta prática.

Do ponto de vista científico, há um desconhecimento por parte da população sobre a influência ambiental que os cadáveres têm quando dispostos em um cemitério. Observando o cenário brasileiro, é alarmante a forma como as necrópoles vêm sendo gerenciadas. Em muito se pode assemelhar um cemitério com um aterro sanitário, visto que em ambos são enterrados materiais orgânicos e inorgânicos. Porém, há um agravante: a matéria orgânica enterrada no cemitério tem a possibilidade de carregar consigo bactérias e vírus que foram a causa da morte do indivíduo, podendo colocar em risco o meio ambiente e a saúde pública (ANJOS, 2013).

Para observar esta questão, é preciso analisar os diferentes tipos de cemitérios, pois os impactos também se dão de forma diferenciada, para isto foi utilizado como base dados apresentados pela empresa Parque Memorial Japi em publicação online e na Resolução ${ }^{\circ} 355$ de 3 de abril de 2003, que indica os principais tipos de necrópoles:

\subsection{Tipos de cemitérios:}

\subsubsection{Cemitério vertical:}

Cemitérios criados como solução para a superlotação e para a questão ambiental, nestes, os sepultamentos são feitos em gavetas localizadas em fileiras. Segundo a Prefeitura de Santa Bárbara, Minas Gerais, lar do primeiro Cemitério vertical público do Brasil, sete sepultamentos verticais usam a área necessária de um túmulo no sistema convencional.

$\mathrm{Na}$ questão ambiental, estes cemitérios “dispõem de sistemas de inibição dos gases do necrochorume e de vedação, para que estes não cheguem às áreas comuns onde circulam os visitantes e funcionários do local" (KEMERICH et al., 2014).

Mesmo com essas vantagens, este tipo de cemitério não é de amplo uso.

\subsubsection{Cemitério tradicional:}

Estes cemitérios possuem uma área aberta para os sepultamentos em contato direto com o solo, e são os mais antigos existentes, geralmente com mausoléus altos e feitos de mármore.

Esse tipo de sepultamento apresenta algumas desvantagens, tais como a possível contaminação das águas subterrâneas e superficiais, a ocupação de grandes áreas, 
devido à preocupação estética há um alto custo na sua construção e manutenção, interferência direta na estética urbana ou do local onde se encontra, e possível proliferação de insetos e animais que podem transmitir doenças, como mosquitos, escorpiões e baratas. (KEMERICH et al., 2014)

\subsubsection{Cemitério jardim:}

São aqueles que contemplam uma grande área verde, com jazidas subterrâneas e pequenas lápides, o paisagismo é muito evidente neste tipo, que comtempla uma boa parcela das necrópoles privadas no Brasil.

Esses tipos de necrópoles apresentam algumas desvantagens, como a falta de tratamento do necrochorume, uma vez que os corpos são enterrados sem que haja uma preocupação com a vedação para os líquidos e gases gerados, o que causa a contaminação do solo e das águas, bem como a possível proliferação de doenças. (KEMERICH et al., 2014)

Figura 2 - Cemitério Grupo Vila - RN

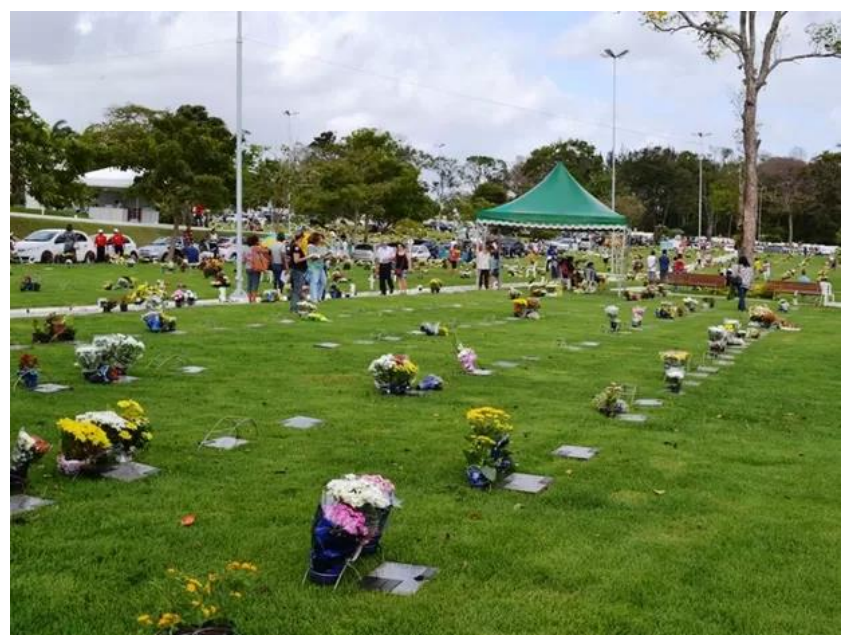

Fonte: Divulgação G1 (2014)

\subsubsection{Crematório:}

Consistem na incineração do material fúnebre, o local para o ato de cremação é formado por fornos e filtros, algumas das principais desvantagens encontradas são alguns gases liberados na combustão, e a pouca popularidade por este meio (KEMERICH et al., 2014), que conta com vantagem para a armazenagem, já que ela não será feita em cemitérios e sim pela famílias que recebe uma urna com o conteúdo, não tendo o contato com o solo nem o problema de superlotação.

Observando estes fatos, é possível perceber que a adoção dos cemitérios verticais e a cremação no setor público e privado, seria de grande ganho ambiental e social, facilitando assim, a disponibilidade de túmulos e a gestão de estoques deste segmento. 


\section{Metodologia}

Para o desenvolvimento desta pesquisa, cuja finalidade é de explorar e analisar a gestão de estoques em cemitérios públicos e privados, foram feitas consultas em artigos e livros sobre a problemática, e sobre assuntos relacionados, buscando a fundamentação nestes estudos, para a construção de uma análise científica sobre o objeto de estudo.

Primeiramente, foram observadas as questões da superlotação e da má estrutura dos cemitérios do setor público, e de como funciona a aquisição de uma acomodação para o material funerário, nos âmbitos público e privado, para isso foram coletados dados através de sites de empresas do segmento e em artigos.

Para parâmetro de comparação entre a rede pública e privada, foi utilizado como base um estudo de caso feito no Cemitério Municipal de Resende e informações sobre cemitérios privados em geral, fazendo a busca online sobre essas empresas.

A comparação foi feita analisando principalmente: o impacto ambiental, a forma de aquisição dos túmulos e os custos envolvidos em ambas, os principais tipos de cemitérios utilizados pelas redes pública e privada e em como o giro de estoque funerário varia de acordo com o tipo de organização.

Também foram realizadas buscas de dados sobre os tipos de necrópoles, e sobre o impacto ambiental trazido por essas organizações, analisando os cemitérios verticais, comuns, jardins e crematórios.

Ocasionalmente serão feitas entrevistas com funcionários de redes de cemitérios privados do estado como o Grupo Vila para uma expansão na coleta de dados.

Este estudo tem ênfase na análise documental e bibliográfica para obtenção de informações, fazendo uma interseção de ideias visando o alcance do objetivo.

\section{Resultados}

Para a exposição dos resultados, foi construída uma tabela apontando as principais divergências, entre os cemitérios da rede pública e da rede privada, para isto, serão utilizados dados obtidos em entrevistas realizadas em janeiro de 2020 com a gestão do Grupo Villa (rede privada), e dados obtidos online sobre a situação dos cemitérios públicos de Natal/RN 
administrados pela Secretaria Municipal de Serviços Urbanos (Semsur), em matérias publicadas pelos portais G1 - RN, Tribuna do Norte e pela Prefeitura de Natal.

Tabela 1 - Comparação de dados Cemitérios Públicos e Privados

\begin{tabular}{|c|c|c|}
\hline Dados & $\begin{array}{c}\text { Cemitérios Públicos de } \\
\text { Natal/RN }\end{array}$ & $\begin{array}{c}\text { Cemitérios Privados do } \\
\text { Grupo Vila }\end{array}$ \\
\hline Sistema de armazenagem & $\begin{array}{l}\text { O município possui } 8 \\
\text { cemitérios, que são } \\
\text { insuficientes para } \\
\text { demanda, sendo assim, em } \\
\text { situações com grandes } \\
\text { quantidades de mortes como } \\
\text { ocorreu em } 2017 \text { com o } \\
\text { Massacre de Alcaçuz, vários } \\
\text { corpos ficaram sem destino } \\
\text { por algum tempo. }\end{array}$ & 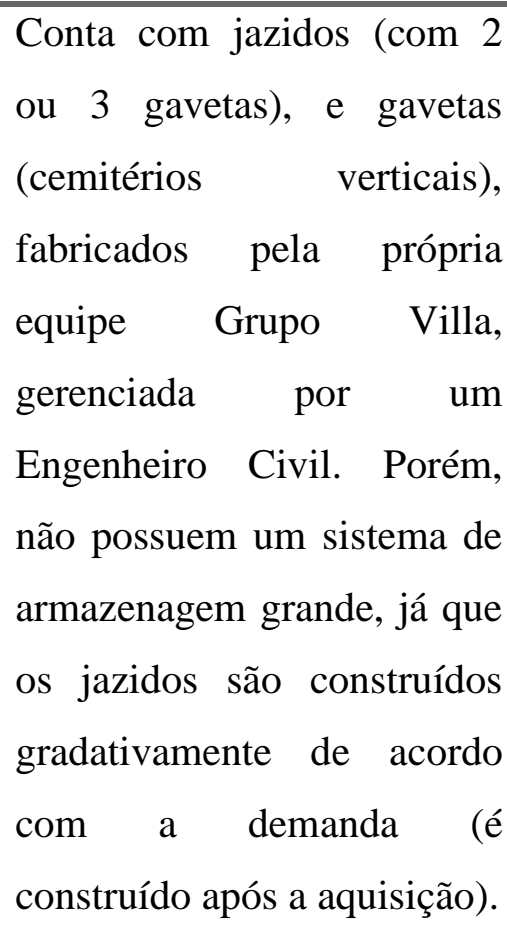 \\
\hline Previsão de novas Obras & $\begin{array}{l}\text { Os cemitérios públicos de } \\
\text { Natal contam com o } \\
\text { problema da superlotação, } \\
\text { mesmo assim, existem obras } \\
\text { paradas desde } 2007 \text { no } \\
\text { Cemitério do Planalto, o } \\
\text { local com } 128 \text { mil m², nunca } \\
\text { foi utilizado para } \\
\text { sepultamentos e está } \\
\text { abandonado. }\end{array}$ & $\begin{array}{l}\text { O Grupo Vila tem previsão } \\
\text { de inauguração de mais } 5 \\
\text { cemitérios até o final de } \\
2021 \text {, sendo um deles } \\
\text { inaugurado nos próximos } 3 \\
\text { meses em São José de } \\
\text { Mipibu e Catolé do } \\
\text { Rocha/PB no final de } 2020 \text { e } \\
\text { outros estão a definir a } \\
\text { ordem de construção. }\end{array}$ \\
\hline Questão Ambiental & \begin{tabular}{lll} 
Uma & das & \multicolumn{2}{c}{ principais } \\
justificativas & dadas pela \\
Semsur em & 2011 para o \\
atraso das & obras no
\end{tabular} & $\begin{array}{l}\text { As construções são } \\
\text { realizadas apenas com a } \\
\text { autorização do Instituto de } \\
\text { Defesa do Meio Ambiente }\end{array}$ \\
\hline
\end{tabular}




\begin{tabular}{|c|c|c|}
\hline & $\begin{array}{l}\text { Cemitério do Planalto, é a } \\
\text { falta de impermeabilização } \\
\text { no solo da região o que } \\
\text { poderia contaminar os } \\
\text { lençóis freáticos de Natal. } \\
\text { As condições ambientais em } \\
\text { outras necrópoles em } \\
\text { atividade na região, como no } \\
\text { Cemitério Bom Pastor I, } \\
\text { também não são agradáveis, } \\
\text { com jazidos abandonados e } \\
\text { prejudicados pelo } \\
\text { vandalismo, lixo e a falta de } \\
\text { impermeabilização. }\end{array}$ & $\begin{array}{l}\text { (IDEMA), também contam } \\
\text { com uma Bióloga } \\
\text { consultores ambientais, para } \\
\text { a realização das obras. }\end{array}$ \\
\hline Tipos de Cemitérios & $\begin{array}{l}\text { Em sua maioria cemitérios } \\
\text { tradicionais. }\end{array}$ & $\begin{array}{l}\text { Modelos } \quad \text { parque/jardim } \\
\text { (jazidos), vertical } \\
\text { crematório humano e Pet. }\end{array}$ \\
\hline
\end{tabular}

Fonte: Entrevistas realizadas pelas autoras e bancos de dados online (2020)

Com isso, podemos observar o abismo entre ambas as redes, que se deve principalmente à diferença de administração, a rede privada fornece maior apoio aos seus clientes, desde a venda e administração de produtos (Caixões, planos...etc.) até o transporte e inumação do material funerário. A gestão pública possui debilidade em algumas áreas, tais como: giro de estoque; capacidade máxima de estoque e a própria gestão estabelecida pelo governo.

O desnível também se deve aos investimentos, que em um caso é de responsabilidade do governo, já o outro, está diretamente ligado ao contrato de clientes.

Com a análise da pesquisa entre os cemitérios públicos e privados deixa perceptível que, o sistema de armazenagem da rede pública não está preparado para um aumento extraordinário de inumação. O massacre ocorrido na penitenciária de Alcaçuz no Rio Grande do Norte transpareceu a debilidade nos cemitérios públicos, na época houve uma grande falha, pois, eles não estavam preparados para esse aumento na demanda e ocasionou essa 
vulnerabilidade dos corpos sem terem um sepultamento adequado. Já a rede privada não sofre com esses impasses pois se a demanda sobe, a produção de novos jazidos e gavetas são construídos, diretamente proporcional para o melhor serviço para os seus clientes.

Se o número de túmulos encontrasse inferior ao grande número de demanda, é necessário a construção de novas necrópoles. O Grupo Vila opta pelo aumento de cemitérios de acordo com o acréscimo de óbitos. porém alguns cemitérios públicos de Natal/RN são insuficientes tendo obras paradas desde 2007 nessa situação negativa.

A preservação do meio ambiente é um assunto muito importante que deve ser tratado com prudência, mesmo assim, alguns cemitérios públicos agem de forma irresponsável utilizando terrenos geograficamente inapropriados para a instalação das necrópoles já que se trata de uma especialidade poluente, sem autorização de órgãos responsáveis pelo serviço. Já o grupo Vila implanta suas necrópoles em terrenos que são aptos para esse serviço.

\section{Considerações finais}

Esta pesquisa apresentou o objetivo de analisar e comparar as gestões de cemitérios públicos e privados, evidenciando a necessidade e a importância socioambiental, de uma boa gestão neste ramo.

Diante do exposto nos resultados, podemos concluir que os cemitérios públicos precisam urgentemente de mais atenção e investimento do governo, para combater transtornos ambientais e a superlotação, para isso, além do investimento monetário, um investimento em novos tipos de sepultamentos, como o método de crematório, presente na maioria das operações de necrópoles privadas, seria de grande reflexo na melhoria das questões expostas ao longo da pesquisa.

\section{REFERÊNCIAS}

ANJOS, Roberta Maas dos. cemitérios: uma ameaça à saúde humana? CREA - SC, [s. 1.], 2013. Disponível em: http://www.crea-sc.org.br/portal/index.php?cmd=artigosdetalhe\&id=2635\#.Xe23sehKjIV . Acesso em: 8 dez. 2019.

ARAUJO, Tulio. O "Jus Sepulchri": Conceito e definições. In: O "Jus Sepulchri". [S. 1.], 2015. Disponível em: https://tmack.jusbrasil.com.br/artigos/241206048/o-jus-sepulchri Acesso em: 12 dez. 2019.

BOSQUE DA ESPERANÇA E PARQUE RENASCER (Belo Horizonte). Cemitério particular x cemitério público: qual escolher? In: Cemitério particular x cemitério público: qual escolher? [S. 1.], 2019. Disponível em: https://cemiteriosemmisterio.com.br/cemiterioparticular-ou-cemiterio-publico/ . Acesso em: 8 dez. 2019. 
DANTAS, Lucas Cortez; FERNANDES, Rubens Matheus Pinheiro; OLIVEIRA, Suzana Melo; PEGADO, Erika Araújo da Cunha. das condições ambientais do cemitério público bom pastor i em Natal/RN: um estudo de caso. das condições ambientais do cemitério público bom pastor i em natal/rn: um estudo de caso, Minas Gerais, 22 maio 2015

KEMERICH, Pedro Daniel da Cunha et al. A questão ambiental envolvendo os cemitérios no Brasil. Revista Monografias Ambientais, [s. 1.], 2014.

PARQUE MEMORIAL JAPI (São Paulo). Tipos de cemitério: você sabe quais são e qual a diferença entre eles? In: Tipos de cemitério: você sabe quais são e qual a diferença entre eles? [S. 1.], 1 set. 2017. Disponível em: https://g1.globo.com/sao-paulo/sorocabajundiai/especial-publicitario/parque-memorial-japi/a-natureza-acolhendo lembrancas/noticia/tipos-de-cemiterio-voce-sabe-quais-sao-e-qual-a-diferenca-entreeles.ghtml . Acesso em: 8 dez. 2019.

PAULA, L. S. Planejamento da Capacidade de Cemitérios: Um Estudo de Caso no Cemitério Municipal de Resende. Monografia (Bacharel em Administração de Empresas). Rio de Janeiro. UNESA, 2005.

PAULA, Luciano Sacramento de; SABBADINI, Francisco Santos. Gestão do planejamento da capacidade em cemitérios municipais. UNESA, [s. 1.], 2005.

RESOLUÇÃO CONAMA N 335, DE 3 DE ABRIL DE 2003 PUBLICADA NO DOU NO 101, DE 28 DE MAIO DE 2003, SEÇÃO 1, PÁGINAS 98-99. Resolução nº 355, de 3 de abril de 2003. Dispõe sobre o licenciamento ambiental de cemitérios. [S. 1.], 2003.

TAVARES, Andréa; MIRALHA, Ediana. Em Natal, Itep tem ossadas e corpos acumulados sem identificação. In: Em Natal, Itep tem ossadas e corpos acumulados sem identificação. Rio Grande do Norte, 23 fev. 2017. Disponível em: http://g1.globo.com/rn/riogrande-do-norte/noticia/2017/02/em-natal-itep-tem-ossadas-e-corpos-acumulados-semidentificacao.html . Acesso em: 8 fev. 2020.

TRIBUNA DO NORTE (Rio Grande do Norte). Cemitério do Planalto está abandonado. In: Cemitério do Planalto está abandonado. Rio Grande do Norte, 20 fev. 2011. Disponível em: http://www.tribunadonorte.com.br/noticia/cemiterio-do-planalto-esta-abandonado/173420 . Acesso em: 8 fev. 2020. 